\title{
Review of ground-based methods to measure the distribution of biomass in forest canopies
}

\author{
Dominik Seidel • Stefan Fleck • Christoph Leuschner • \\ Tom Hammett
}

Received: 29 March 2010 /Accepted: 26 August 2010/Published online: 18 March 2011

(C) The Author(s) 2011. This article is published with open access at Springerlink.com

\begin{abstract}
- Context Ecological research and an effective forest management need accurate information on the structure of the forest canopy to understand the biochemical, physiological and biogeochemical processes within a forest.

- Research question This paper reviews the currently available instruments for measuring the distribution of biomass within forest canopies. We compare the most well-established approaches and present the different measurable parameters. A special focus lies on the resolution of the obtained data.

- Results It was found that only 3D laser scanners offer data with the resolution required by ecologists, private landholders, the forest industry and the public to detect trends in tree growth patterns and canopy interactions in all three spatial dimensions. But data validation, data analysis and parameter extraction are still under development, and the price of the instrument is quite high.

- Conclusion Research should focus on the parameter extraction from terrestrial laser scanner data as this could allow the calculation of functional attributes for different sections of a canopy on a high spatial resolution. It could also help ecologists characterize the structure of forest stands in a quick and precise way.
\end{abstract}

\section{Handling Editor: Gilbert Aussenac}

D. Seidel $(\varangle) \cdot$ S. Fleck $\cdot$ C. Leuschner

Plant Ecology, Albrecht-von-Haller-Institute of Plant Sciences, University of Göttingen,

Untere Karspüle 2,

37073 Göttingen, Germany

e-mail: dseidel@gwdg.de

T. Hammett

Department of Wood Science and Forest Products, Virginia

Polytechnic Institute and State University,

Blacksburg, VA, USA
Keywords Forest canopies · Biomass distribution · 3D information

\section{Introduction}

Forests cover about $30 \%$ of the earth's mainland, and the surfaces of forest canopies are the main gateways regulating the exchange of energy, carbon and water vapour between terrestrial ecosystems and the atmosphere (FAO 2001; Law et al. 2001; Parker et al. 2004). The structure of a forest canopy influences the quantity, quality and spatial and temporal distributions of light in the stand, which in turn affects the presence or absence of ground vegetation and influences temperature, relative humidity, and the physiological activity of tree organs (leaves, fruits, woody organs) and many other organisms within a forest (Jennings et al. 1999; Kobayashi and Iwabuchi 2008).

Because of the complexity of the 3D forest canopy structure, most canopy measurement research has focused on parameters that may serve as a surrogate for the $2 \mathrm{D}$ or 3D canopy structure, such as leaf area index (LAI), average leaf inclination angle (ALIA), aboveground biomass (AGBM), canopy clumping index $(\Omega)$ or foliage density (Chen and Black 1992; Kucharik et al. 1999; Gower et al. 1999; Drake et al. 2003; Jonckheere et al. 2004; Takeda and Oguma 2005).

Some of these variables, e.g. LAI or AGBM, can be obtained from airborne platforms (Running et al. 1986; Chen and Cihlar 1996; Lefsky et al. 1999; Hyyppä et al. 2008). However, for an effective forest management, especially for ecological research, it is desirable to obtain information about the distribution of the biomass in a forest plot at a higher resolution, especially higher than that currently available by remote sensing (Watt et al. 2003). Such data could be used to detect trends in the commercial 
and biodiversity conservation values of forests and might serve for the purpose of carbon accounting (Tickle et al. 2006). Additionally, there is a need of methods for collecting ground truth data and for obtaining detailed information on canopy stand structure where remote sensing technologies are 'blind' (Gong et al. 1998; Lovell et al. 2003; Hopkinson et al. 2004; Næsset et al. 2004; Pfeifer et al. 2004; Korhonen et al. 2006).

Until now, sampling of the complete spatial heterogeneity of a canopy has been difficult as it can neither be directly measured nor can it be estimated with indirect approaches. The main reasons are that the number of needed measurements is large and errors are too high (Jennings et al. 1999; Jonckheere et al. 2004). Hence, parameters that could serve as surrogates are still important. While it is significant to integrate or simplify descriptors in all those cases where a direct relationship to total biomass or volumetric density is given, the suitability of these parameters is questionable, especially during an assessment of forest functions. Functional processes such as gas exchange or radiation interception are often speciesspecific and can usually not be explained by vegetation density on its own (Larcher 2003).

Since forest management concentrated on converting monocultures into diverse mixed-species stands, which are economically and ecologically more beneficial (Olsthoorn et al. 1999; BMBF 2003, 2004; Spiecker 2003; von Lüpke et al. 2004; Schraml and Volz 2004), forests and their canopies became more heterogeneous and therefore their 3D structure became more relevant. The hitherto prevalent assumption of vertical or horizontal canopy homogeneity as used in forest models needs to be revised for trees in a forest stand as there are shade and sun leaves as well as young and old leaves (Boardman 1977; Ashton 1978; Koike et al. 1990; Canham et al. 1994; Parker et al. 2004). Even the sunlight penetration, and thereby the distribution of direct and diffuse light, cannot be explained on the 2D level (Pretzsch and Schütze 2005). As Pretzsch and Schütze (2005) pointed out, "the fact that sunlight does not come vertically from above but is absorbed or modified when passing through canopy layers, calls $2 \mathrm{D}$ concepts into question" (p. 631).

In the literature, some promising results of modelling the spatial distribution of light or biomass in a canopy in two (2D) or three (3D) dimensions are presented (Aber and Federer 1992; Canham et al. 1994; Lovell et al. 2003; Hopkinson et al. 2004; Takeda and Oguma 2005). But a number of methods are suggested which are simply not practical for evaluating biomass distribution for large areas (Koike 1985; Kurachi et al. 1986; Sumida 1995).

The objective of this paper was to review the major direct and indirect terrestrial methods for measuring the distribution of biomass in forest canopies and to identify gaps in the technology. Precise information on the distribution of the biomass is needed to increase the quality of models of radiation, interception or wind velocity within a stand. Having detailed information on the structure allows scaling from branch to tree level, or from tree to stand level. This will help understand processes within the canopy and interactions between forests and the atmosphere as well as between forest and the pedosphere. Furthermore, we depict the needs for future research on instruments allowing to gain these information. A discussion of the advantages and disadvantages of the various approaches, as well as the expectations of future applications, will be given. A classification of two groups was used: (a) direct methods (destructive) and (b) indirect methods (non-destructive). Prior to the introduction of the methods, we will present the parameters that can be measured and how they are defined.

\section{Suitable parameters and their definitions}

In this review, we do not focus on the mathematical procedures used to derive all parameters introduced but will briefly present their definition. For those who are interested in the mathematical sources, we will cite appropriate literature. One of the most important parameters is the LAI (see Fig. 1). It has been redefined many times as reviewed by Jonckheere et al. (2004). Hence, it is important to point out which definition is used in a study. According to Jonckheere et al. (2004), LAI is defined as one half of the total leaf area per unit ground surface area in current literature.

A number of studies recommended the use of the term plant area index (PAI, see Fig. 1) to separate data gained from direct LAI measurements from those of indirect measurements. Indirect approaches do not allow separating between photosynthetically active and inactive biomass, and therefore, the actually measured parameter is the whole plant area (PAI, woody and non-woody plant material) instead of the photosynthetically active area only (Parker et al. 2004; Henning and Radtke 2006; Van der Zande et al. 2006). PAI can be considered as one half of the total area of all plant surfaces per unit of ground area (Henning and Radtke 2006). Walcroft et al. (2005) suggested using effective $L A I\left(L_{\mathrm{e}}\right)$ to distinguish between woody and foliage surfaces if measured with optical methods. In this review, we used the term PAI when talking about optically (indirect) retrieved 'LAI' data that included woody and non-woody plant material. Surface area index, SAI, is the total foliage surface area per canopy volume (Welles and Cohen 1996, p. 1336). Canopy closure is defined as the percentage of ground shaded by overhead foliage (Daubenmire 1959, cited in Ganey and Block 1994). 


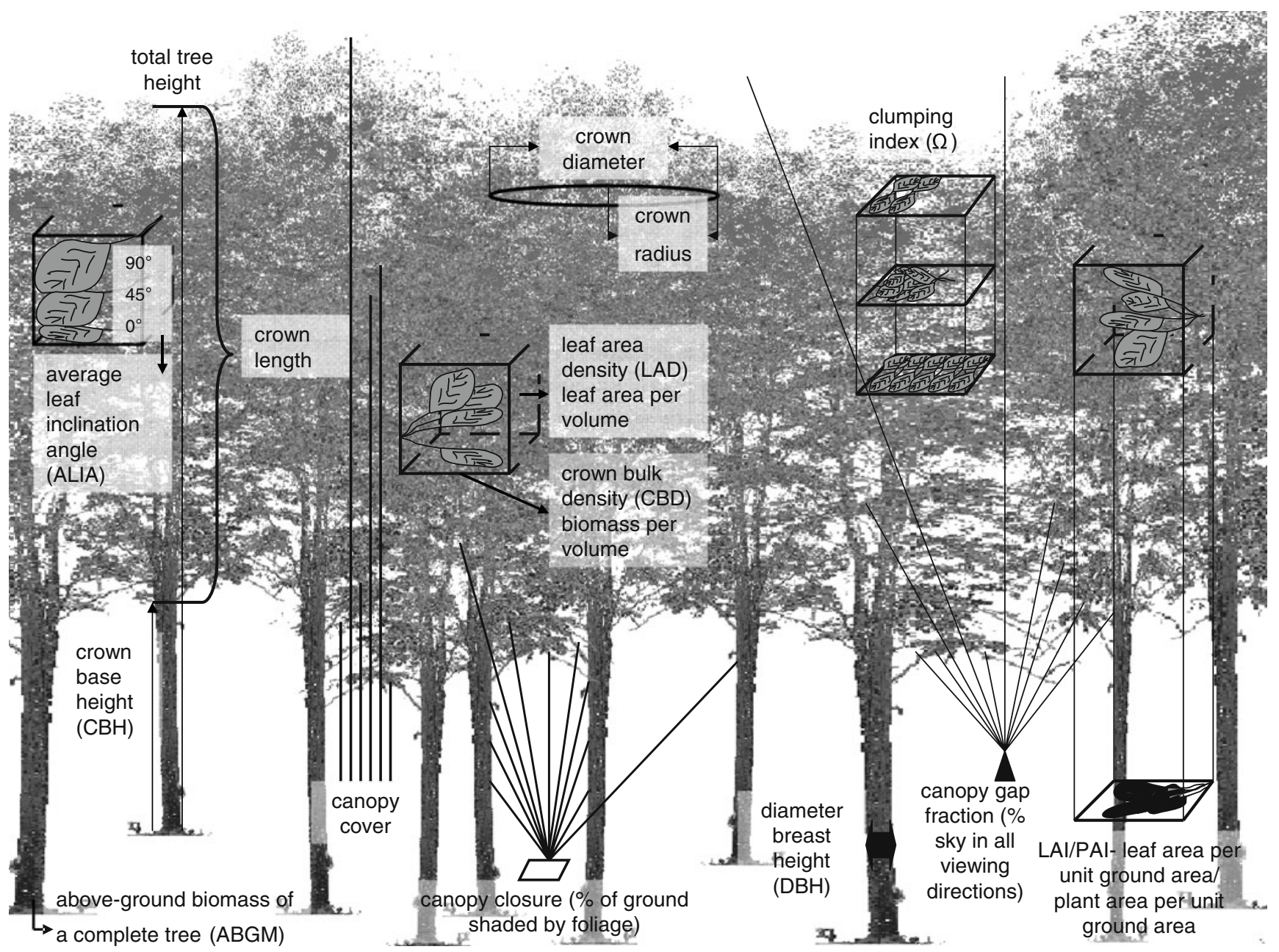

Fig. 1 Forest canopy, its major characteristics and the main biomass parameters presented in the text

Confusion about similar parameters has been clarified by Jennings et al. (1999). Canopy gap fraction, which is the fraction of view that is unobstructed by the canopy in any particular direction (Welles and Cohen 1996), is similar but not identical to canopy closure (see Fig. 1).

The term leaf area density (see Fig. 1) is useful if the volumetric density of a canopy is to be described. It is defined as total leaf area per canopy volume (Welles and Cohen 1996). The foliage density, defined in Koike (1985) as the expected value of leaf number penetrated by a straight line within a unit distance, is identical with the relative frequency or percentage frequency in Wilson (1959, $1960,1965)$ or the density of foliage in MacArthur and Horn (1969).

Detailed information about the orientation of foliage objects is given by the ALIA (see Fig. 1) which describes the angle between leaf surface and horizontal plane (Takeda and Oguma 2005). The randomness of the distribution of foliage in a canopy can be quantified with the clumping index $(\Omega$, see Fig. 1$)$, which was first affiliated by Nilson (1971) and is used to describe the degree of systematic arrangement of foliage in a canopy (Nilson 1971). As a comprehensive description of the amount of the existing biomass above the ground, the AGBM (see Fig. 1) does not distinguish between green and non-green biomass or between herb- or tree-layer vegetation (Drake et al. 2003). Figure 1 gives a graphical overview of the major characteristics of a forest canopy and important biomass parameters.

It is obvious from the great variety of parameters that we need various methods to describe and measure all these different canopy characteristics. In the following, we present ground-based methods to determine the mentioned parameters.

\section{Direct methods}

Direct methods use instruments that have direct contact to the material of investigation (e.g. a leaf) and that are able to determine the desired parameters without using mathematical derivations. The term destructive methods is also used as the investigated objects are usually damaged during the measurement. 
As these methods are of high accuracy, they were often used as reference for other approaches (e.g. Jonckheere et al. 2004; Thimonier et al. 2010). Although nowadays there are already other techniques used for validation (Lovell et al. 2003; Hopkinson et al. 2004; Morsdorf et al. 2006), the direct methods are still regarded the best choice.

\subsection{Allometrics}

Allometric relations are based on the determination of a relationship (correlation) between characteristics of two different plant organs, e.g. the diameter at breast height and the total height of a tree. Thereby, one parameter is measurable and the other one is the non-measurable (or difficult to measure) parameter of interest. If the biomass distribution is the parameter to be estimated, allometric relations could be based on the destructive collection of the foliage of certain branches with known diameter. The characteristics of the sampled plant material, e.g. the leaf area of a branch with a certain basal diameter, can then be assigned to the entire tree, and even to other trees of the same species if the diameters of the according branches can be measured. It is crucial to develop a statistical model that describes the relationship between branch diameter and the leaf area of this branch exactly enough (Bartelink 1997). Therefore, one can say that it can be laborious and timeconsuming to establish an allometric formula with a satisfying degree of accuracy and many samples are needed (Gower et al. 1999). Many biomass formulas (allometric relations) are available to estimate difficult to measure parameters for different species based on easier to measure parameters, such as diameter at breast height $(\mathrm{DBH}$, see Fig. 1), branch basal area, tree height or others (Whittaker and Woodwell 1968; Hashimoto 1990; Niklas 1994; Gower et al. 1999; Porté et al. 2002; Pretzsch and Schütze 2005; Pretzsch 2006). Special software has been developed to predict biomass parameters based on existing equations (e.g. BIOPAK, Means et al. 1994). If not reconfirmed by casespecific calibration (e.g. leaf collection in the stand of interest), allometric relations could also be considered as an indirect method. However, the establishment of an allometric formula found in the literature has once been based on a destructive sampling, at least to achieve validation measurements (Gower et al. 1999). Therefore, we classify allometric relations as direct methods.

\subsection{Stratified clipping and the scaffolding approach}

'Stratified clipping' is based on a harvest of all plant elements within defined height layers. The harvest is repeated for different height levels (canopy strata) to get a vertical profile of the foliage density (Monsi and Saeki 1953; Fujimori 1971; Aber 1979). Here, a horizontal analysis of foliage allocation, for instance to investigate clumping effects, would be possible. This method is timeconsuming (Aber 1979); thereby, especially in complex structured natural forests, it is only applicable to small canopies or single trees. Allometric relations are often based on such exhaustive measurements on single trees, which might not be feasible in protected areas. However, collecting all leaves of a tree is an exact way to determine its leaf area or biomass, and the data can be used for further analysis, such as leaf age or health assessment of the tree. The extraction of vertical leaf-area distributions has been the main goal of stratified clipping as presented in the literature (Kira et al. 1969; Waring et al. 1982).

The scaffolding approach is a special form of stratified clipping. Fukushima et al. (1998) tested the accuracy of the 'MacArthur-Horn method' (MacArthur and Horn 1969; see Section 4) with a harvesting approach combined with allometrics using a scaffolding in the forest. The scaffolding consisted of cells of a defined size, spread over different height levels. All leaves inside each cell were counted and partly harvested. Allometric relations were then used to estimate the stand's foliage density. Here, as an improvement to stratified clipping, the horizontal biomass distribution can also be described (Fukushima et al. 1998). A big disadvantage is that the use of a scaffolding in a forest is strongly limited by the topographic conditions, understory density and stand height (Barker and Pinard 2001).

Most direct harvest approaches potentially fulfil the requirements for a reconstruction (in $2 \mathrm{D}$ or $3 \mathrm{D}$ ) of the sampled tree or stand canopy structure, even though the effort might not be worthwhile. In fact, direct methods are extremely laborious, if not impracticable, if complete canopies of mature trees are to be investigated (Aber 1979). But there is no other way for a validation of the indirect methods.

\subsection{Litter traps}

A widely used direct non-harvest method is the traditional litter trap which is at least 40 years old (Ovington 1963; Marshall 1968; Heller 1971; Ellenberg et al. 1986). The litter fall of leaves or needles is collected in traps of various designs that are adequate to collect the litter and allow for water penetration to prevent decomposition (Daniel 1975; Tanner 1980; Chason et al. 1991; Dufrêne and Bréda 1995; Takeda and Oguma 2005). What material is collected is determined by wind and gravity combined with the primary position of the leaf or needle in the stand. Researchers advise that this method should only be used in deciduous forests with autumn leaf fall (Jonckheere et al. 2004) as leaf age is an interesting factor when analysing the collected material (Lowman 1988). The analysis of the collected material is rather easy but time-consuming. Leaf area is 
calculated by scanning the leaves with a flat bed scanner and using software (e.g. WinFolia, RegentInstruments, Quebec, Canada) to calculate the area of exemplary leaves (Lendzion and Leuschner 2008). Leaf weight and other parameters can be determined after drying the samples in an oven. The exact procedure is known as the 'gravimetric method' and is a tool to define the green leaf area-to-dry weight ratio, which is crucial if litter trap data shall be assigned to the plot level (Jonckheere et al. 2004). Continuing the separation by species to analyse speciesspecific parameters is as well possible as an additional check for diseases, leaf age and other characteristics (Lowman 1988; Luizao 1989; Takeda et al. 2008). In contrast to the other direct methods, information on the spatial distribution in all three dimensions is insufficiently available by this approach, which is a big disadvantage as a forest stand is not homogeneous in any direction. Setting up a large number of litter traps per area unit could be used as a statistical solution to get information on a higher level of spatial resolution, but would not be feasible (Jonckheere et al. 2004). Litter traps are often used for validating new methods (e.g. McIntyre et al. 1990; Thimonier et al. 2010) and are assigned to the direct methods even though they are not destructive (Sampson and Allen 1995; Mussche et al. 2001; Jonckheere et al. 2004). However, litter traps are clearly different from the other direct approaches.

\section{Indirect methods}

In contrast to the direct methods, indirect approaches are based on mathematical derivations or assumptions which are used to calculate the desired parameter from another easily measured parameter (Jonckheere et al. 2004). Indirect methods are not based on an active collection of plant material and are therefore not destructive. They can be separated into indirect contact methods that require contact between the measuring instrument and the plant and indirect non-contact methods that operate without any contact to the plant.

\subsection{Indirect contact methods}

\subsubsection{Point quadrat method and inclined point quadrats}

The theory behind the indirect contact methods is based on investigations developed in the 1930s. Levy and Madden (1933) introduced the point quadrat method whereupon thin needles were passed through grassland or low-vegetation canopies (up to 1.5-m height) in an upward direction. The contacts between the needle and the green foliage were recorded and the ratio of non-contact shots to contact shots was then used as a measure of the leaf area above a predefined quadrat of ground area (Levy and Madden 1933).

In 1960, Wilson (1960) published an improved model, the inclined point quadrats approach. Extensive tests led Wilson to the conclusion that only sloped needle shots which are perpendicular to an inclined ground area quadrat were able to estimate the LAI with satisfying accuracy. He recommended an inclination angle of $32.5^{\circ}$ at which LAI became equal to 1.1 times the average number of leaf contacts per needle (Wilson 1960; Jonckheere et al. 2004). It is important that either the needle or the leaves had to be randomly distributed according to the compass direction (Barkman 1988) as the mathematics would otherwise be limiting. Suggestions and practical evidence on how to further improve the inclined point quadrat were given and reviewed by Jonckheere et al. (2004). Dufrêne and Bréda (1995) compared the use of a sharp and a blunt needle and found the results to be significantly linearly related to litter trap data, but systematically lower in a range of $6-37 \%$. Measuring biomass distribution by counting contacts and non-contacts with a measurement tool in a manual way is difficult to conduct and is a time-consuming and labourintensive work. In addition, it is difficult to retrieve contact or non-contact data even for small canopies, such as grass (e.g. Knight 1973). Firstly, it is not easy to bring a needle or something similar into the canopy without disturbing it, and secondly, it is difficult and thereby subjective to determine whether there is a contact or not. Jonckheere et al. (2004) pointed out that there is still the problem that at least 1,000 insertions should be done to achieve reliable results. As long as the insertions are to be done manually, all improvements according to the used instruments or even automated contact detection (Jonckheere et al. 2004; Weiss et al. 2004) will not significantly increase the applicability of the method to tall forest canopies.

\subsection{Indirect non-contact methods}

Non-contact methods are also known as 'optical' methods (Fassnacht et al. 1994; Chen and Cihlar 1996; Kucharik et al. 1998; Walcroft et al. 2005) as they are based on optical measurements. Typically retrieved parameters are foliage density, ratios of photosynthetically active radiation (PAR) between above and below the canopy, canopy closure, and many others (Koike 1985, 1989; Welles and Norman 1991; Stenberg et al. 1994; Guevara-Escobar et al. 2005). The canopy gap fraction is an important surrogate for LAI or PAI, and it can also be determined based on indirect noncontact methods (Welles and Cohen 1996). Canopy gap fraction is essentially identical to the parameter derived from the inclined point quadrat methods (ratio of noncontact shots to contact shots when observed in skyward viewing direction). 


\subsubsection{MacArthur and Horn's photographic method}

The 'MacArthur and Horn' photographic method allows the determination of the ratio of sky to plant area in a photograph made in an upward direction from under the canopy. The photograph is covered with a grid of lines, and the per cent cover of the canopy is estimated by the per cent of grid squares with more than 50\% covered (MacArthur and Horn 1969). Originally, the method was developed to estimate vertical foliage profiles by recording the heights where a plant element intersects with a vertical line virtually drawn to infinity above the intersecting points of the grid on the camera. The camera is usually moved randomly along a transect. PAI and the vertical distribution of the AGBM can finally be calculated from these data (Fukushima et al. 1998; MacArthur and Horn 1969). Aber (1979) further improved the method and named it 'optical point quadrat method'. Both, the 'MacArthur and Horn' photographic approach and the optical point quadrat method used by Aber (1979) have some similarities to the methods presented in Section 4.2.3, but are treated separately in this paper due to their photographic character.

\subsubsection{Hemispherical photography}

Hemispherical photography is another photographical approach which actually predates the 'MacArthur and Horn' photographic method. In the 1890s, there were suggestions to use photographs to assess 'the effect of obstruction on irradiation at a site' (Riblet 1951 cited in Anderson 1964). These thoughts were the basics for the invention of the hemispherical or 'fisheye' photography. In 1924, Hill published his idea of 'a lens for whole sky photographs' and created a lens with a simple equidistant (polar) projection (Hill 1924). In the following years, advancements of Hill's lens with a field of view of up to $180^{\circ}$ were brought to the market and used widely (Evans and Coombe 1959; Anderson 1964, 1966; Madgwick and Brumfield 1969; Bonhomme and Chartier 1972; Pope and Lloyd 1975; Nilson and Ross 1979; Herbert 1987). Equidistant polar projections thereby prevailed against competitors with mathematically more difficult projection types (Anderson 1964; Rich 1990; Jonckheere et al. 2004). Still, distortions caused by the lens may introduce errors in the results and should be corrected (Herbert 1987). Anyway, hemispherical photography enables the analysis of many other parameters more than PAI, such as light penetration or leaf angle distribution (Rich 1990). In an analogy to the aforementioned non-contact method, hemispherical photographs can offer gap fraction data (canopy openness, see Fig. 1) that allow for the estimation of PAI, transmitted radiation and other parameters (Koike 1989; Hardy et al. 2004). The images need to be processed to separate pixels representing plant material and pixels representing the sky according to their grey values and a simple threshold procedure (e.g. Frazer et al. 1999; Englund et al. 2000). Therefore, hemispherical photographs need to be transformed to grey scale when made as colour images and are to be taken in an upward direction with the camera being levelled. Camera settings should be optimized for high contrast between plant and sky. To get a workable black-to-white contrast, there should be a uniformly overcast sky to prevent direct radiation causing illumination effects in the picture and thereby leading to misclassifications between sky and plant material, which is the basis of the analysis of hemispherical photographs. Only pictures with high contrast allow successful, automated, less subjective and fast image processing. Analysis software is available from several manufacturers (e.g. WinScanopy, RegentInstruments; CanEye, www.avignon.inra.fr/can_eye; or Gap Light Analyzer, Simon Fraser University, Burnaby, BC) and others more. Discussions on suitable camera settings (Chen et al. 1991; Macfarlane et al. 2000; Jonckheere et al. 2004; Zhang et al. 2005) as well as on the thresholding procedure and its subjectivity (Anderson 1964; GuevaraEscobar et al. 2005; Zhang et al. 2005) can be found in the literature. In addition, there are publications available on the differences between the results from analogue and digital cameras (Frazer et al. 2001). The 3D biomass distribution can be estimated from hemispherical photographs if the sampling design is appropriate (Ondok 1984). A type of hemispherical photography with similar characteristics but with an included software that processes the images directly is the digital plant canopy imager (CI-110, CID Bioscience, WA, USA). It is not treated as an extra method here as it is basically identical to hemispherical photography in the manner of generating the data, but doing the analysis in real-time (Bréda 2003; Keane et al. 2005).

In the past, data retrieved from such photos were useful for ecological studies and were often used as a validation for novel measurement techniques, such as light detection and ranging (LIDAR, see next section) instruments (Brunner 1998; Lovell et al. 2003; Hopkinson et al. 2004; Morsdorf et al. 2006).

\subsubsection{LIDAR and optical point quadrat methods}

LIDAR instruments have recently been used as 'optical point quadrat' methods and were tested for giving reliable gap fraction data. Optical point quadrat sampling means that the traditional needle as used in the (inclined) point quadrat method to detect contact and non-contact shots is substituted by a laser beam (Vanderbilt et al. 1979; Lovell et al. 2003; Parker et al. 2004; Takeda et al. 2008). Until now, the method was mainly used for small canopies or 
crops (Vanderbilt et al. 1979; Walklate 1989), but attempts to measure forest canopies are also reported (Lovell et al. 2003). The LIDAR unit emits a laser beam in a certain direction and receives a signal if the beam was reflected by an object. Consequently, contact shots are equivalent to reflected laser beams that reach the receptor unit of the instrument and non-contact shots are equivalent to nonreceived shots. Systems provide a range from simple single-direction laser pointers to $2 \mathrm{D}$ or even complete $3 \mathrm{D}$ laser scanners, whereas tripod-based approaches exist as well as portable ones (Welles and Cohen 1996; Blais 2004; Fleck et al. 2004; Dias 2006; Hosoi and Omasa 2007). Not all of these instruments have been successfully applied to tall forest canopies.

Three-dimensional laser scanners can be used in a multiple scan design to create $3 \mathrm{D}$ models of the scanned scene based on more than one perspective. The scanner is moved to different positions in and around the investigated scene, in which artificial targets are fixed to allow the combination of the scans in the computer in one common coordinate frame (Hopkinson et al. 2004; Pfeifer et al. 2004; Dold and Brenner 2006; Henning and Radtke 2006; Van der Zande et al. 2006; Fleck et al. 2007). The scanning procedure is usually fast and can be done in a few minutes for a full hemisphere with a state-of-the-art scanner, e.g. the Z+F Imager 5006i (http://www.zf-laser.com/e_index.html) or the FARO laser scanner photon (http://laser-scanner.faro. com/faro-laser-scanner-photon/) and others more. However, the transformation of all scans to one coordinate system requires a time-consuming registration process and strong computer hardware, which can make the post-processing rather expensive.

The use of terrestrial laser scanners (TLS) is usually restricted to what is visible from the ground even if different perspectives are used. Approaches mounting the scanner on a mobile lift to get a better overview are rather seldom (Loudermilk et al. 1997). Anyway, obstruction effects can never be totally eliminated. This causes a general trend of less data in the uppermost part of the investigated scene as the laser beams are already reflected by lower canopy elements (Chasmer et al. 2004; Hosoi and Omasa 2007; Takeda et al. 2008).

Publications show that TLS is en route to become a powerful tool to measure the $3 \mathrm{D}$ distribution of the biomass of a forest in a never seen resolution, speed and comprehensiveness (Lovell et al. 2003; Henning and Radtke 2006; Takeda et al. 2008). Automatical measurements of length and diameter of tree trunks and individual branches, including the changes in their radii (Pfeifer et al. 2004), are as well possible as tree lean, sweep and taper (Watt et al. 2003; Thies et al. 2004), gap fraction, PAI and LAI (Lovell et al. 2003; Chasmer et al. 2004; Henning and Radtke 2006; Danson et al. 2007; Takeda et al. 2008). Most of these applications are still under development, and validation remains a problem (Pfeifer et al. 2004; Van der Zande et al. 2006).

\subsubsection{Radiation measurement}

The LI-Cor Line Quantum sensor LI-191 (LI-Cor Bioscience, Lincoln, NE, USA) and other linear sensors measure the ratio between the PAR under the canopy and above the canopy, usually with a two-sensor sampling allowing for simultaneous measurements. The sensor itself consists of a metre-long quartz rod covered with a glass that filters non-PAR radiation. Canopy closure (see Fig. 1) and PAI can be estimated from these data as they are related to the gap fraction of the canopy that allows PAR to penetrate (Martens et al. 1993; Stenberg et al. 1994; Welles and Cohen 1996; GuevaraEscobar et al. 2005), and thereby, conclusions on the biomass distribution can be drawn. This is done based on the Lambert-Beer law and was described in detail by Monsi and Saeki (1953), including formulas and derivations which will not be repeated here.

Other PAR Line Quantum sensors are the Sunfleck Ceptometer (Decagon Devices, Pullman, WA, USA), in the modified versions called SunLink and AccuPAR, and the SunScan SS1 (Delta-T devices, Cambridge, GB; Dufrêne and Bréda 1995; Welles and Cohen 1996). The Sunfleck Ceptometer and its descendants consist of 80 small sensors spaced $1 \mathrm{~cm}$ apart on a linear probe, all measuring the incoming PAR independently from each other allowing the estimation of a sunfleck distribution. The SunScan SS1 reads data from two ceptometer-like sensors parallel to calculate LAI by a light model (Welles and Cohen 1996).

Kucharik et al. (1998) pointed out that the assumed random distribution of foliage elements, underlying the theory to derive LAI (or PAI) from indirect measurements, is frequently called into question (Kucharik et al. 1998). As the Lambert-Beer law (Jarvis and Leverenz 1983; Marshall and Waring 1986) and the 1D inversion model (Norman and Campbell 1989), which are usually used for the computation of the LAI (or PAI) from non-contact instruments (Monsi and Saeki 1953), are only valid in homogeneous media, they have to be corrected with the clumping index $(\Omega) . \Omega$ is used to account for non-randomness at the shoot, branch, crown or canopy level that occurs in every canopy (Lang and Yueyuin 1986; Stenberg et al. 1994; Chen and Cihlar 1995b; Dufrêne and Bréda 1995; Weiss et al. 2004; Leblanc et al. 2005; Walcroft et al. 2005; Morsdorf et al. 2006).

The hemispherical sensor LI-Cor LAI-2000 (LI-Cor Bioscience) is the consequent advancement of the LI-Cor Line Quantum sensors LI-191. The indirect estimate of the biomass distribution is based on the theoretical relationship between leaf area and canopy transmittance, which is the actually measured parameter (Welles 1990). PAI is 
calculated from measured radiation via inversed radiation models as introduced above (Jarvis and Leverenz 1983; Marshall and Waring 1986; Norman and Campbell 1989). The LAI-2000, also named 'plant canopy analyzer', therefore uses five photo diodes which are arranged in concentric rings and measure the relative irradiance below $490 \mathrm{~nm}$ for different sky sections. The canopy transmittance is then computed for the different sections as the ratio of below to above canopy radiation for each ring. Below and above canopy readings need to be done without a big time delay and under overcast sky conditions that remain uniform (Li-Cor 1992; Wang et al. 1992; Stenberg et al. 1994; Welles and Cohen 1996; Guevara-Escobar 2005).

\subsubsection{TRAC and MVI}

In 1995, Chen and Cihlar invented the tracing radiation and architecture of canopies (TRAC) instrument (Chen and Cihlar 1995a) to give estimates of the clumping factor $(\Omega)$ as needed for reliable data from indirect non-contact measurements of PAI or LAI. $\Omega$ is calculated by analysing the canopy gap size distribution. Canopy gap fraction is thereby analysed as a function of solar zenith angle (Chen and Cihlar 1995b; Kucharik et al. 1998, 1999). The TRAC uses three Li-Cor LI-190 SB PAR sensors, two facing the sky and one facing the ground, and calculates the ratio of total PAR to reflected PAR. For coniferous tree species, it is not yet possible to determine $\Omega$ on a scale larger than the shoot level, neither with the TRAC nor with the MVI (see below), as mentioned by Chen et al. (1997).

Shortly after the TRAC was brought to the market, Kucharik et al. (1998) presented the multiband vegetation imager (MVI). The MVI allows distinguishing leaves from branches using a two-band (Visible, 400-620 nm, and near-infrared, 720-950 nm) image pair of the investigated scene (Kucharik et al. 1998), which is a unique and useful feature. The spatial relationship between branches and photosynthetically active foliage can thereby be measured with this instrument as well as $\Omega$, the clumping factor (Kucharik et al. 1998).

Both, TRAC and MVI, are based on measurements of the net radiation and have been intended to measure $\Omega$, but not LAI, PAI or other canopy parameters, which makes them different from the other instruments presented here. However, they were included into this review as the clumping factor is also regarded as an important parameter to determine biomass distribution information.

\subsubsection{DEMON}

The DEMON (Assembled Electronics, Yagoona, NSW, Australia) is an instrument used to measure the direct beam transmission of the sun in canopies. Calculations are thereby also based on measurements of the canopy gap fraction as a function of zenith angle. The DEMON is faced directly to the sun whilst the operator is standing under the canopy, and the incoming radiation is filtered to a band near $430 \mathrm{~nm}$ and then captured in a photocell. The acceptance angle of the photocell is limited to only $0.302 \mathrm{sr}$, and thereby, diffuse radiation from $95 \%$ of the upper hemisphere is eliminated. The measurements have to be repeated and averaged over different sun angles, and they require some knowledge about $\Omega$ from other instruments, such as MVI or TRAC, to give reliable results (Lang et al. 1985; Lang 1990; Welles and Cohen 1996; Kucharik et al. 1998).

\subsubsection{Spherical densiometer}

The classical 'spherical densiometer' is widely used to retrieve forest canopy parameters, such as canopy closure and, hence, the forest light environment, optically (Knowles et al. 1999; Englund et al. 2000). It is an inexpensive and simply constructed instrument invented in the 1950 s (Lemmon 1956, 1957). Consisting of a convex or concave mirror with an overlaid grid of squares, the spherical densiometer is handheld horizontally at elbow height whilst the operator takes at least four sampling positions (Cook et al. 1995; Fiala et al. 2006). Some authors classified the spherical densiometer as a quick and reasonably precise method to determine the long-term light environments, even though it is faced with the problem of subjectivity (Englund et al. 2000). Others stated that results of the spherical densiometer are weakly correlated to other instruments but not influenced by subjectivity (Engelbrecht and Herz 2001), whilst, again, others say that the accuracy of the obtained data is often questionable especially due to subjectivity (Ganey and Block 1994). Cook et al. (1995) even named their paper: "Spherical densiometers produce biased estimates of forest canopy cover". (Cook et al. 1995). However, to minimize operator effects, measurements should be done by only one experienced operator and with a densiometer fixed on a tripod and being levelled (Lemmon 1956; Strickler 1959; Vales and Bunnell 1988; Ganey and Block 1994). Many instruments exist that are similar to the spherical densiometer and that allow visual estimates of canopy closure, and we will name them for the sake of completeness: line intercept (Canfield 1941), non-spherical densiometers (Stumpf 1993) or the vertical tube (Johansson 1985). Other ocular estimates exist, but they are usually used to define canopy characteristics of the understory vegetation (Walters and Soos 1962; Van Hees and Mead 2000).

\subsubsection{The Moosehorn}

The Moosehorn is a simple handheld instrument which can be used to measure the canopy density and the crown 
closure. Basically, it consists of a long box with a glass on the top end and a grid printed on this glass. The box is to be held vertically in a way that the glass faces directly the sky (a bubble level is useful). On the bottom end of the box is a sighting aperture that allows seeing the glass with the grid via a mirror. The operator's head is thereby in a natural orientation with eyes being parallel to the forest floor, which makes it easier to count the number of dots in the grid not covering canopy material. The proportion of dots covering canopy material and those covering the sky is related to the canopy density. Repeated measurements are necessary to get reliable results. Out of 25 dots in the grid, only the central one is projected vertically. The remaining dots are projected in angles between $1.8^{\circ}$ and $5.1^{\circ}$ from vertical, which could cause some bias, as well as the difficulty to hold the whole instrument vertically for the period needed to count all grid points (Robinson 1947; Garrison 1949; Bonnor 1967).

\section{Comparison of techniques and discussion}

After the introduction of the most well-established methods, we found that depicting 'the best' approach is difficult. Indirect approaches were shown to be less laborious than direct methods, but the type of data gained from indirect approaches is quite different in terms of what is actually measured. In addition, due to a less straightforward measurement, the data are often more difficult to interpret. The fact that all indirect methods, except for the TLS, tend to underestimate the LAI (or PAI) due to foliage clustering is well known (Nackaerts et al. 1999). Another contributing factor is that optical approaches are more or less blind of what is behind the first object in each and every viewing direction (Aber 1979; Watt et al. 2003; Watt and Donoghue 2005; Van der Zande et al. 2006), which could also result in an underestimation of the present biomass (Bréda 2003). Therefore, each method has its advantages and disadvantages.

We used a catalogue of criteria that enabled us to evaluate the quality of the methods and their suitability to fulfil the given task: providing 3D biomass distribution data for forest canopies in a comprehensive way. The criteria were:

- Where or under which conditions are measurements possible

- Required weather conditions

- How accurate is it and what is the spatial resolution

- What computer resources are needed

- How long does it take

- How much does it cost

- How much effort is the post-processing of the data

- What are the general advantages and disadvantages
These criteria were evaluated based on experiences reported in the literature. Giving concrete numbers, e.g. for the price of an instrument, would fail. Prices change, they differ between countries, and depend on configurations. If the amount of time needed for a measurement is to be compared for different instruments, it depends on many more aspects than the instrument alone. How easy is the access to the object of investigation and how big is it? What kind of transportation is available? Which level of accuracy is desired? How experienced is the user?

Hence, we decided to use relative ranges for prices, the time required for a measurement, accuracy and resolution, and the needed computer resources. This allowed a comparison of the methods relative to each other. We will not discuss the topographical restrictions of the instruments, such as measurement errors, due to slope effects because most of these restrictions are of a rather theoretical nature. It is more a question of the amount of additional effort that is necessary to use a method on a slope that decides whether it will be done or not than actually the overall applicability. An example would be the scaffolding approach, which would be more complicated on a steep terrain but is not generally impossible. For indirect methods, often, mathematical solutions exist to correct for topographic effects in the data, such as those presented by Schleppi et al. (2007) for hemispherical photographs. The decision if a method is used for a study is to a certain extent dependent on the topography as one factor characterizing the study site, but there are others more that have to be taken into account, such as infrastructure (road access, electricity) or available time. Such a priori limitations should not be incorporated into a review of the methods.

\subsection{Where or under which conditions were measurements possible}

In this section, we compare the applicability of the different approaches. We found that the direct methods, even though they featured data with the highest accuracy, faced the biggest limitations according to the spatial information of the extracted data, especially if $3 \mathrm{D}$ information is of importance, as it is difficult and expensive making a complete harvest of a mature tree (Aber 1979). To protocol the origin of the collected material on a high spatial resolution (e.g. centimetres) is extremely laborious. The access to the canopy itself could be limited as dense understory vegetation would hinder the complex instrument setup, such as the installation of a scaffolding (Barker and Pinard 2001). In addition, the destructive character of some direct methods does not allow repeated measurements and can be problematic in National Parks due to nature protection polices. Using allometric relations from the literature could be a solution to the problem of the 
destructive character of the method and the hampered canopy access. But it would still be difficult to separate the characteristics of individuals from those that are speciesspecific. A large number of statistically independent samples would be necessary to solve this problem, which would be laborious (Jonckheere et al. 2004). However, there would still be a lack information on the 3D distribution of the biomass as it would not assign a position ( $x y z$ coordinates) to the material.

The point quadrat approaches in their traditional form were designed for shrub or grassland canopies and can only be applied to rather small and simply structured trees as the operator needs to see whether there is a contact between the needle and the canopy (Groeneveld 1997). For taller canopies, the instrument itself is impracticable as an easyto-carry telescope stick would be hard to handle once they exceed a certain length. Using optical point quadrat measurements would solve these problems for two reasons. Firstly, there is no longer a stick (with the needle on top) which could bend or swing and, secondly, there is no need to see the object hit by the laser beam (Lovell et al. 2003). Anyway, some optical point quadrat methods were invented rather for crops than for large trees (e.g. Vanderbilt et al. 1979; Walklate 1989).

The indirect non-contact methods were regarded to be applicable to a broader range of forest canopy types. Limitations are rare. The Li-Cor Line Quantum sensors and the LAI-2000 require simultaneous above or beneath canopy measurements (Welles and Cohen 1996; Machado and Reich 1999). Either an open field or a tower/stick reaching above the canopy is therefore needed, which should not be a problem in most cases.

\subsection{Required weather conditions}

A complex forest canopy is difficult to describe in detail even without wind-induced movements. Hence, the absence of wind or gusts is the most crucial precondition for a successful measurement of the biomass distribution in a forest canopy. All presented approaches require calm wind, even though the tolerance against constant breezes or gusts might be different for each method. TLS is one of the methods that is very sensitive to wind-induced movements of the study object as it has a very high spatial resolution (millimetres) detecting even small changes during the scanning (e.g. Haala et al. 2004). Traditional point quadrat methods are also strongly hindered by wind as movements of the leaves make contact detections difficult (e.g. Radtke and Bolstad 2001). Litter traps have to work under any weather conditions. The theory used to gain results from litter traps, which is based on the assumption that the leaves do not fall far from their origin in the canopy, tends to fail under windy conditions. Anyway, Staelens et al. (2003) found that "prevailing wind directions during leaf litter fall affected leaf dispersal in a broad-leaved deciduous forest" (Staelens et al. 2003).

Precipitation (rain as well as snow) might be disadvantageous for most field work, but is totally intolerable for those methods based on optical measurements: TLS, photographic approaches, MVI, densiometer and Moosehorn. Raindrops may also cause errors in the light measurements, and some instrument even need direct sunlight. The photographical approaches (MacArthur and Horn method, hemispherical photos) require a uniform overcast sky to prevent high contrast in the brightness of the sky (Zhang et al. 2005), but measurements are also possible during dawn and dusk of a day with clear blue sky (e.g. Welles and Cohen 1996). Instruments measuring the radiation (quantum sensors, ceptometer, SunScan SS1) or canopy reflectance (TRAC, MVI) or direct beam transmission (DEMON) require constant direct sunlight for reliable results. The LAI2000 is best used under uniform overcast sky conditions (e.g. Wang et al. 1992). Litter traps have the highest tolerance for any kind of precipitation as long as drainage is ensured.

\subsection{Accuracy and resolution}

Whilst the accuracy of a method can be high (results correlate with an accepted validation method), the resolution can be low at the same time. An example would be the litter traps. The method is well established and is used for the validation of other methods (Mussche et al. 2001). The accuracy is therefore regarded to be high, but the resolution of the method is rather low as there is no information for a certain tree or branch that could be extracted. As all direct methods are of high accuracy, the indirect methods can only be evaluated using direct methods for validation (Fukushima et al. 1998; Arthur et al. 2000; Mussche et al. 2001). Their direct character may be laborious (Aber 1979), but it is the only way to gain reliable validation data. In Table 1, we listed appropriate literature that allows evaluating the accuracy of each indirect method. The resolution of the methods was classified based on the level of detail in the spatial data that can be from the methods, e.g. 'tree level' would mean that the measured parameter can be extracted for a single tree, but not for a certain branch.

Point quadrat methods showed a satisfying accuracy (e.g. Wilson 1960; Dufrêne and Bréda 1995), but offer only a low resolution as the number of contacts within the total number of shots to the canopy is a spatial average (Levy and Madden 1933; Goodall 1952) and is useful on the canopy level only, even though heights at which contacts occur can also be protocolled (Wilson 1963).

Indirect non-contact methods have a wide variety in their accuracy and resolution as they are based on a variety of 


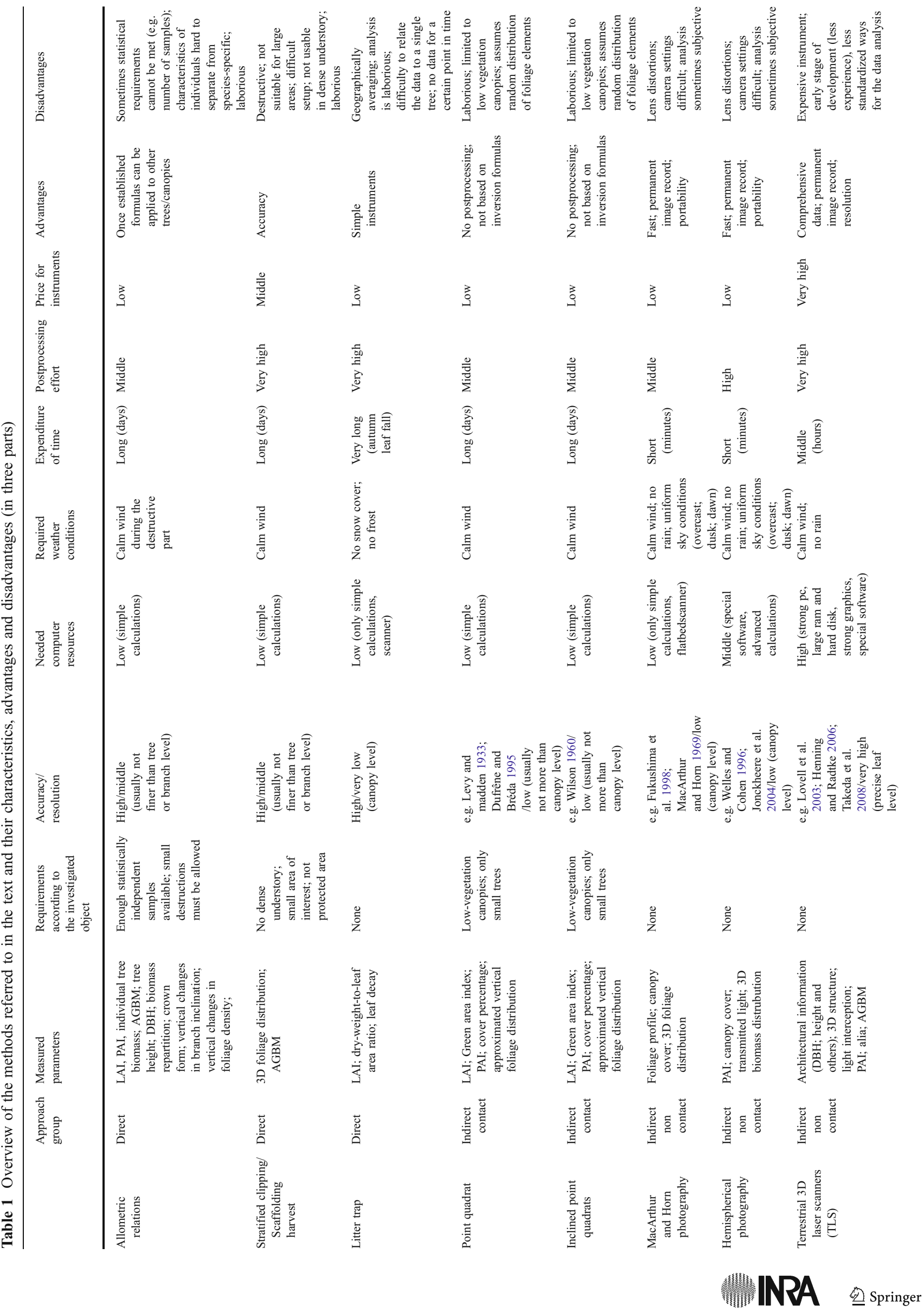




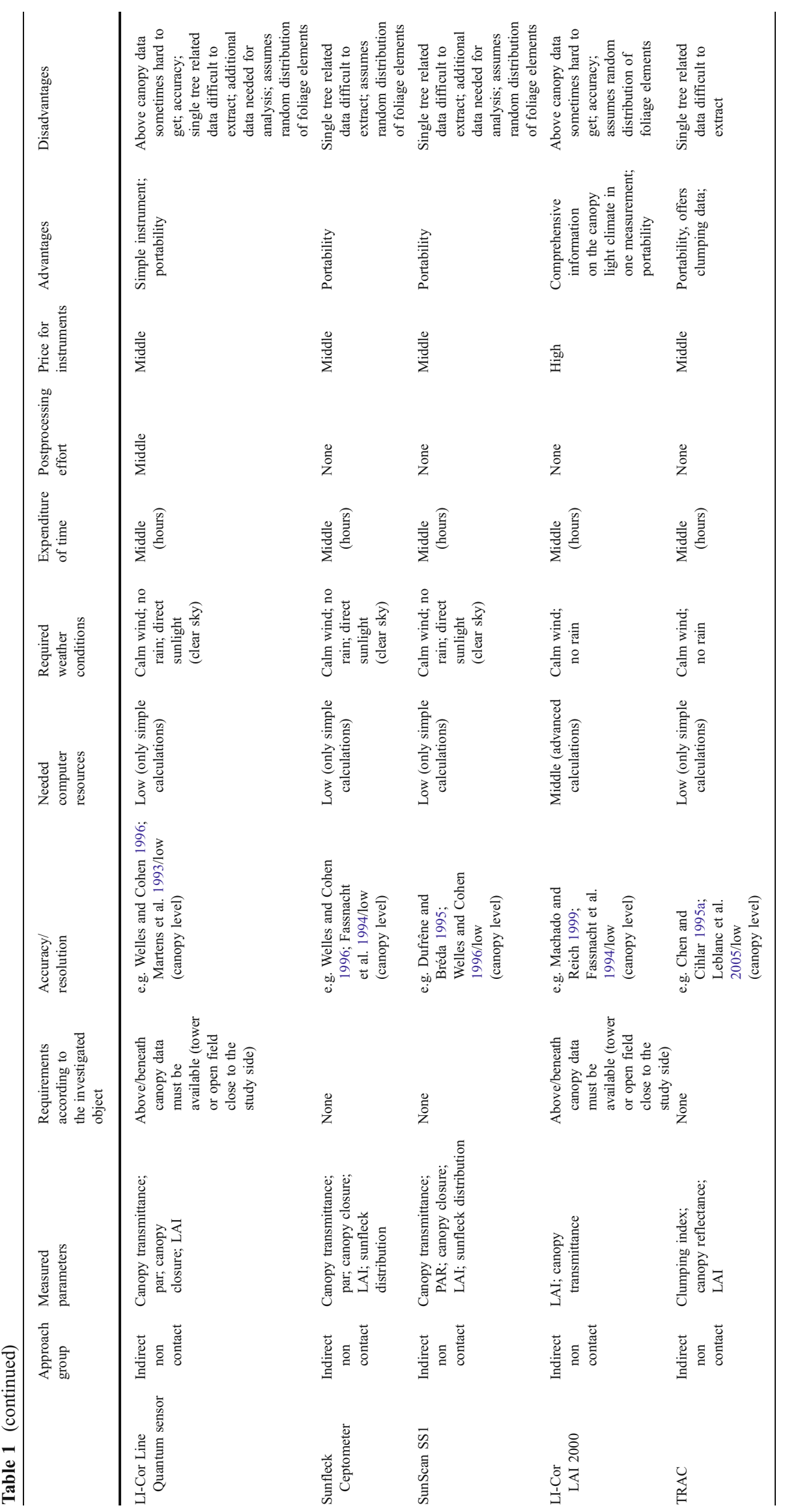


measurement techniques and sensors (Jonckheere et al. 2004). Low precision in the spatial assignment (resolution) of 3D information can already be gained with the Line Quantum sensor, the ceptometer and the SunScan SS1 as these instruments are strongly averaging over the measured area. Measured radiation values are always related to a certain part of the canopy depending on the field of view of the instrument (Lang and Yueyuin 1986; Welles 1990). The accuracy of estimated biomass values is thereby dependent on the used light model and its assumptions (Welles and Cohen 1996) as well as on the accuracy of the determination of some input parameters required, such as the extinction coefficient, which are often not measured but estimated (Welles 1990).

Hemispherical photographs and images taken with the MacArthur and Horn method are only used to describe certain parts of a canopy (low resolution, only canopy level). They have been shown to be a reliable LAI source and were used for the validation of other methods (Brunner 1998; Lovell et al. 2003; Hopkinson et al. 2004; Morsdorf et al. 2006). Higher resolution might be possible when using cameras with a finer image resolution (e.g. Leblanc et al. 2005), but results can still not be assigned to certain elements of the canopy as the $3 \mathrm{D}$ forest structure is transferred to the $2 \mathrm{D}$ photographic information and thereby one dimension is lost. A special sampling design at least allows a limited 3D data extraction from hemispherical photographs (Ondok 1984). TRAC, LAI-2000 and MVI offer data on a similar level of resolution and accuracy as hemispherical photographs do (Welles and Cohen 1996; Rhoads et al. 2004; Leblanc et al. 2005), whereas some authors saw the LAI-2000 to be in favour (Machado and Reich 1999).

DEMON, spherical densiometer and Moosehorn data are of rather low spatial information content (resolution) as results are given for the tree or canopy level and vertical information is not available. (Bonnor 1967; Welles and Cohen 1996; Englund et al. 2000; Engelbrecht and Herz 2001). This is true for all indirect non-contact methods, except for the terrestrial laser scanner. TLS is able to give complete 3D models (resolution: very high) of the scanned forest (e.g. Watt et al. 2003; Hosoi and Omasa 2007), but there are still problems in the use of the data. Modelling algorithms and data extraction are difficult and obstruction effects in the upper part of the canopy as well as validation are still challenging (Chasmer et al. 2004; Van der Zande et al. 2006). However, the accuracy of parameters derived from TLS is promising (e.g. Danson et al. 2007; Hosoi and Omasa 2007).

\subsection{Needed computer resources}

Most of the instruments (line quantum sensors, point quadrat sampling, densiometers, Moosehorn) need none or only simple computer resources. MVI, TRAC, DEMON and LAI-2000, as well as hemispherical photography, need some additional software or hardware. The required hardware is today's standard and the software is in many cases available as freeware. The only instrument that needs powerful processors, large RAM and lots of free hard disk space, as well as a strong graphic adapter and expensive software, is the TLS. Moreover, the use of 3D laser scanner data is limited due to problems in the processing of the large datasets (e.g. Pfeifer et al. 2004).

\subsection{Expenditure of time}

Whilst hemispherical photographs and the MacArthur and Horn images can be taken in less than a minute, direct methods usually take days or weeks. The laborious character of direct measurements and point quadrat methods implicates a greater time requirement. Except for the litter traps, which are used over a certain period of time (e.g. autumn leaf fall), all indirect measurements can be done within minutes or hours for a complete canopy. Whenever measurements have to be done periodically, it is easier to use indirect methods. Especially imaging instruments, such as photos, the TLS or the MVI are useful in the monitoring of changes over time. The time ranges presented here are valid under the presumption that one single experienced operator is using the technique, but this might be unrealistic for the harvest methods labour effort. Anyway, the time needed for a measurement differs from operator to operator, which depends on the weather and even changes with the experience a single operator makes by using an instrument. In addition, measurements might not be possible for days due to rain, snow, frost and wind or hindered by transport problems or the general accessibility of the study site. Hence, the time ranges given here are only rough and approximate values.

\subsection{Price for the instruments}

Comparing the prices of a certain measurement, e.g. the price of a LAI information for a forest plot, would not be useful. First, the different resolutions of the instruments would have to be brought in conformity, which is very difficult. Secondly, the price of time and work needed to gain the data differs with the operator's qualification and boundary conditions, such as carrying cost and the consumption of expendable materials. Instrument prices are subject to change, but using relative price classes will help get an overview of the necessary investments.

The most inexpensive instruments are the Moosehorn (Smith et al. 2008), densiometers (Englund et al. 2000), the cameras for the photographical approaches (Englund et al. 2000), the equipment for the point quadrat methods (Aber 1979) and allometric approaches especially for large areas 
using formulas from the literature (Botkin et al. 1993). Using litter traps is already more expensive, not because of the material needed to construct them but due to the fact that they require inspection and service by an employee throughout the year. The harvest approaches are expensive more due to their laborious character than because of the instruments needed. The instrument price increases in relation to the employee's wages when using the MVI, DEMON, TRAC or the instruments measuring the radiation. Even more expensive is the LAI-2000. By far, the biggest investment is the TLS, which is about $50-80$ times the price of a hemispherical camera.

\subsection{Post-processing effort}

When comparing the post-processing effort of the techniques, it can be difficult to separate the actual sampling from the post-processing for some instruments. We decided to call post-processing only what is 'usually' done in the office/lab after the actual field measurement. Of course, nowadays, portable computers allow viewing and processing the data directly at the location of the measurement, but this is not necessarily to be done in field. Hence, it is not sampling anymore but 'postprocessing' in our definition.

Using allometric equations requires some post-processing since the data acquisition in the field is only the input data for the equations that need to be processed later on (Whittaker and Woodwell 1968; Hashimoto 1990; Niklas 1994; Porté et al. 2002; Pretzsch and Schütze 2005; Pretzsch 2006). The harvest techniques as well as the litter trap method need a rather laborious and time-consuming post-processing as plant compartments need to be sorted, dried, weight, scanned, etc. (Monsi and Saeki 1953; Fujimori 1971; Aber 1979; Lowman 1988; Luizao 1989; Lendzion and Leuschner 2008). Less time-consuming are the point quadrat methods as they need calculations and statistics to build the ratio of hits to non-hits between the needle and canopy objects which can be automated (Wilson 1960; Barkman 1988; Jonckheere et al. 2004).

The MacArthur and Horn photography approach also requires some mathematics, but has its emphasis more on the field work than in the post-processing (MacArthur and Horn 1969).

Hemispherical photography analysis is done using software packages that require input parameters for the calculation (e.g. WinScanopy, RegentInstruments; CanEye, www.avignon.inra.fr/can_eye; or Gap Light Analyzer, Simon Fraser University, Burnaby, BC) and some interventions by the operator that may be time-consuming. Whilst it takes only seconds to make a hemispherical photograph, it can take a couple of minutes to calculate LAI values or other parameters based on the image.
Terrestrial laser scanning is probably the indirect method that is most post-processing-intensive. Whilst highresolution full-hemisphere scans can be taken in $<4 \mathrm{~min}$ (e.g. ZF Imager 5006, Zoller and Froehlich $\mathrm{GmbH}$, Wangen, Germany), the extraction of biomass parameters might take a day due to the registration process and the large amount of data that are to be processed. Generally speaking, the more automated the analysis, the less time is needed for post-processing. The lack of standards in the extraction of parameters from terrestrial laser scanning is therefore currently the main reason for the above average time demand of this young technique (Thies et al. 2004; Thies and Spiecker 2004). The analysis of data obtained with Line Quantum sensors is also less standardized and may therefore take some extra time for the user-specific post-processing. Data loggers are to be read out and mathematics have to be applied to calculate the desired parameters (Welles 1990; Leblanc et al. 2002). Using the LAI-2000, the TRAC, the SunScan or the Ceptometer (and its modifications) makes the post-processing obsolete as the measured parameter (LAI) is directly represented on a screen since all calculations are automatically derived by the internal software. Strongly reduced manual postprocessing is also given with the incorporated canopy image analysis techniques of the MVI (Jonckheere et al. 2004). The DEMON has an incorporated parameter calculation as well. However, both instruments need to be read out with a computer for the final data evaluation, even though there is no 'real' post-processing (Jonckheere et al. 2004). The last two instruments, the spherical densiometer and the Moosehorn, do not require post-processing. The ratios of obstructed and unobstructed grid cells can be evaluated directly in the field and there is no data logging available (Bonnor 1967; Englund et al. 2000).

\subsection{Advantages and disadvantages}

In this section, we present the general advantages and disadvantages of each method.

Allometric relations showed good results in the past (e.g. Bartelink 1997; Porté et al. 2002), and once established, they do not require a lot of field work. Disadvantages are the mean resolution and the fact that characteristics from individuals are difficult to separate from those that are species-specific (Jonckheere et al. 2004).

Stratified clipping and a scaffolding harvest are also methods of high accuracy, but only mean resolution. The assembling in the field can be difficult for the methods that require the active collection of plant compartments, and they are too laborious to be used for practical applications in tall canopies or over large areas. Additionally, an excessive disturbance of the studied forest plot is often not tolerable. 
Litter traps have a big advantage: the literature offers lots of reference data from studies in the past as it is an old and simple method. The passively collected material allows determining parameters such as the dry weight-to-leaf area ratio, and results can be compared to those of older studies. The accuracy in the estimation of such parameters might be high, but the resolution is weak. Information on a certain point in time is not extractable as well as single tree-related data or precise 3D information. It is impossible to prevent leaves from distant trees to be blown into a trap far away (resolution: very low). In addition, the analysis of the collected matter in the lab is laborious. As a matter of completeness, the low price of this method should be mentioned as an advantage.

All indirect methods are rather fast and non-destructive, which is a general advantage for these kinds of measurements. However, disadvantages are as manifold as the approaches. Both point quadrat methods are unfortunately not suitable for large canopies. The assumption of random distribution of the foliage elements is also a drawback (Whitehead et al. 1990; Chason et al. 1991).

Hemispherical photography and the MacArthur and Horn method are fast, they produce permanent image records, and they are rather inexpensive and easy to carry. The problems are more in the detail. Camera settings are sensitive to the weather and the image analysis is not free of subjectivity. MacArthur and Horn images are prone to distortions in the images, which is not completely eliminated in the hemispherical lenses as well (Herbert 1987; Schwalbe 2005).

The TLS application to extract 3D biomass distributions is in an early stage of development. Therefore, prices are extremely high and standardized ways of data extraction in the form of algorithms are rare. However, TLS may offer unique spatial information in a comprehensive way and with a unique resolution. The image character of the data allows analysing a variety of architectural parameters, and their number increases with ongoing research. However, validation is still a problem as the destructive sampling of a complete laser scan scene is difficult. Standardized protocols for TLS data interpretation are also rare. Portability and expenditure of time needed to capture a canopy are additional TLS benefits to be mentioned here.

An easy portability is a key benefit of the Moosehorn and the spherical densiometer. Others are their extremely low prices and the usage independently from any computer accessibility. Anyway, these simple instruments are prone to subjectivity and are of low resolution according to the 3D character of the canopy structure data that can be obtained. Again, as for the point quadrat methods, a random distribution of foliage elements is assumed (Barkman 1988), which is another con (Whitehead et al. 1990; Chason et al. 1991).
An advantage of the Line Quantum sensor, the Sunfleck Ceptometer and the SunScan SS1 is mainly their portability. The extraction of 3D data, especially those which are single tree-related, is impossible due to the low resolution. The assumption of random foliage distribution is again a simplification of the reality and considered to be a disadvantage.

The LAI-2000 also uses this theoretical restriction with the same negative consequences in the analysis. Anyway, it offers comprehensive information on the canopy light climate in one measurement, which can be used to derive sophisticated LAI values; unfortunately, the reference is difficult to be extracted thereby (low resolution).

TRAC and MVI can be used to gain clumping data, which is a unique advantage. Both instruments are easy to carry, and the MVI can even be used to extract information on the photosynthetically active material alone. Again, a big disadvantage is the non-given possibility to assign the results to a certain part of the canopy (low resolution).

Table 1 gives a summary of the characteristics of each method in the compared categories.

\section{Conclusions}

Depending on the aim of the study, different compromises concerning the used methods appeared to be inevitable. Each method has been proven to be useful and has shown its advantages and disadvantages. The demand for new methods is always connected with open research questions, new fields of investigation or new findings.

The increasing relevance of the 3D structure of forest canopies for current research tasks, especially in ecology, generates a rising need for instruments offering detailed spatial information (Lovell et al. 2003; Parker et al. 2004; Takeda and Oguma 2005; Pretzsch and Schütze 2005).

If a fast measurement of high-resolution and real 3D information ( $x y z$ coordinates of all objects) is of the highest priority, the TLS should be chosen as it is the only method that could offer such data with a reasonable effort. Destructive methods are not an alternative due to the nonarguable effort they would require for mature forest canopies, especially if the high-resolution 3D information is in the focus. The price of a TLS is a hindrance, so is the still difficult and less standardized data analysis. However, studies showed the big potential for the instrument (Lovell et al. 2003; Watt et al. 2003; Hopkinson et al. 2004; Thies et al. 2004; Watt and Donoghue 2005), especially if destructive methods are not applicable due to forest protection policies. Rental of the instruments could alleviate the financial burden as well as a shared purchasing by different institutes or organizations. 
Research is facing the challenge that surrogates for the 3D distribution may no longer be needed as comprehensive 3D data become available from TLS. Up to 500,000 measurements throughout a canopy can be done in $1 \mathrm{~s}$ when using a state-of-the-art 3D laser scanner. Now, algorithms and programmes are needed to extract suitable parameters from the virtual forests.

Research should focus on this data acquisition as this would enable the calculation of functional attributes such as canopy carbon gain, transpirative water loss and processes for different sections of a canopy. Ecologists would be able to characterize the structure of forest stands faster and more precisely than ever.

Acknowledgements The helpful comments of two anonymous reviewers are greatly acknowledged. The work is part of doctoral studies being undertaken by D. Seidel and was funded by the German Research Foundation (DFG).

Open Access This article is distributed under the terms of the Creative Commons Attribution Noncommercial License which permits any noncommercial use, distribution, and reproduction in any medium, provided the original author(s) and source are credited.

\section{References}

Aber JD (1979) Foliage height profiles and succession in northern hardwood forests. Ecology 60:18-23

Aber JD, Federer CA (1992) A generalized, lumped-parameter model of photosynthesis, evapotranspiration and net primary production in temperate and boreal forest ecosystems. Oecologia 92:463474

Anderson MC (1964) Studies of the woodland light climate. 1. The photographic computation of light conditions. J Ecol 52:27-41

Anderson MC (1966) Some problems of simple characterization of the light climate in plant communities. In: Bainbridge R, Evans GC, Rackham $\mathrm{O}$ (eds) Light as an ecological factor. Blackwell, Oxford, pp 77-90

Arthur MA, Hamburg SP, Siccama TG (2000) Validating allometric estimates of aboveground living biomass and nutrient contents of a northern hardwood forest. Can J For Res 31:11-17

Ashton PS (1978) Crown characteristics of tropical trees. In: Tomlison PB, Zimmermann MH (eds) Tropical trees as living system. Cambridge University Press, Cambridge, pp 591-615

Barker MG, Pinard MA (2001) Forest canopy research: sampling problems, and some solutions. Plant Ecol 153:23-38

Barkman JJ (1988) A new method to determine some characters of vegetation structure. Vegetatio 78:81-90

Bartelink HH (1997) Allometric relationships for biomass and leaf area of beech Fagus sylvatica L. Ann For Sci 54:39-50

Blais F (2004) Review of 20 years of range sensor development. J Electron Imaging 13:231-240

BMBF (2003) Zukunftsorientierte Waldwirtschaft. Bundesministerium für Bildung und Forschung, Bonn, p 60

BMBF (2004) Handlungskonzept für den Förderschwerpunkt 20042008. Nachhaltige Waldwirtschaft-Die Bedeutung des Waldes und seiner Leistungen für die Gesellschaft. Bundesministerium für Bildung und Forschung, Bonn, April 2004, p 16

Boardman NK (1977) Comparative photosynthesis of sun and shade plants. Annu Rev Plant Physiol 28:355-377
Bonhomme R, Chartier P (1972) The interpretation and automatic measurement of hemispherical photographs to obtain sunlit foliage area and gap frequency. Isr J Agric Res 22:53-61

Bonnor GM (1967) Estimation of ground canopy density from ground measurements. J Forest 65:545-547

Botkin DB, Simpson LG, Nisbet RA (1993) Biomass and carbon storage of the North American deciduous forest. Biogeochemistry 20:1-17

Bréda NJJ (2003) Ground-based measurements of leaf area index: a review of methods, instruments and current controversies. J Exp Bot 54:2403-2417

Brunner A (1998) A light model for spatially explicit forest stand models. For Ecol Manag 107:19-46

Canfield RH (1941) Application of the line interception method in sampling range vegetation. J Forest 45:388-394

Canham CD, Finzi AC, Pacala SW, Burbank DH (1994) Causes and consequences of resource heterogeneity in forests: interspecific variation in light transmission in canopy trees. Can J For Res 24:337-349

Chasmer L, Hopkinson C, Treitz P (2004) Assessing the three dimensional frequency distribution of airborne and ground based LIDAR data for red pine and mixed deciduous forest plots. Int Arch Photogramm Remote Sens Spat Inf Sci 36:8W/2

Chason JW, Baldocchi DD, Huston MA (1991) A comparison of direct and indirect methods from estimating forest canopy leaf area. Agric For Meteorol 57:107-128

Chen JM, Black TA (1992) Defining leaf area index for non-flat leaves. Plant Cell Environ 15:421-429

Chen JM, Cihlar J (1995a) Plant canopy gap size analysis theory for improving optical measurements of leaf area index. Appl Opt 34:6211-6222

Chen JM, Cihlar J (1995b) Quantifying the effect of canopy architecture on optical measurements of leaf area index using two gap size analysis methods. IEEE Trans Geosci Remote Sens 33:777-787

Chen JM, Cihlar J (1996) Retrieving leaf area index of boreal conifer forests using Landsat TM images. Remote Sens Environ 55:153-162

Chen JM, Black TA, Adams RS (1991) Evaluation of hemispherical photography for determining plant area index and geometry of a forest stand. Agric For Meteorol 56:129-143

Chen JM, Rich PM, Gower ST, Norman JM, Plummer S (1997) Leaf area index of boreal forests: theory, techniques, and measurements. J Geophys Res 102:29429-29443

Cook JG, Stutzman TW, Bowers CW, Brenner KA, Irwin LL (1995) Spherical densiometers produce biased estimates of forest canopy cover. Wildl Soc Bull 23:711-717

Daniel MJ (1975) Preliminary account of litter production in a New Zealand lowland podocarp-rata-broadleaf forest. NZ J Bot 13:173-187

Danson FM, Hetherington D, Morsdorf F, Koetz B, Allgöwer B (2007) Forest canopy gap fraction from terrestrial laser scanning. IEEE Geosci Remote Sens 4:157-160

Dias P (2006) 3D reconstruction of real world scenes using a low-cost 3D range scanner. Comput-Aided Civ Infrastruct Eng 21:486-497

Dold C, Brenner C (2006) Registration of terrestrial laser scanning data using planar patches and image data. In: IAPRS, XXXVI, 5, Dresden, Germany, pp 78-83

Drake JB, Knox RG, Dubayah RO, Clark DB, Condit R, Blair JB, Holfton M (2003) Above-ground biomass estimation in closed canopy Neotropical forests using LIDAR remote sensing: factors affecting the generality of relationships. Glob Ecol Biogeogr $12: 147-159$

Dufrêne R, Bréda N (1995) Estimation of deciduous forest leaf area index using direct and indirect methods. Oecologia 104:156-162

Ellenberg H, Mayer R, Schauermann J (1986) ÖkosystemforschungErgebnisse des Sollingprojekts 1966-1986. Verlag Eugen Ulmer, Stuttgart, p 509 
Engelbrecht BMJ, Herz HM (2001) Evaluation of different methods to estimate understorey light conditions in tropical forests. J Trop Ecol 17:207-224

Englund SR, O'Brien JJ, Clark DB (2000) Evaluation of digital and film hemispherical photography and spherical densiometer for measuring forest light environments. Can J For Res 30:19992005

Evans GC, Coombe DE (1959) Hemispherical and woodland canopy photography and the light climate. J Ecol 47:103-113

FAO (2001) FAO Global Forest Resources Assessment 2000, Main Report 2001. FAO Forestry Paper 140, p 511

Fassnacht KS, Gower ST, Norman JM, McMurtie RE (1994) A comparison of optical and direct methods for estimating foliage surface area index in forests. Agric For Meteorol 71:183-207

Fiala ACS, Garman SL, Gray AN (2006) Comparison of five canopy cover estimation techniques in the western Oregon Cascades. For Ecol Manag 232:188-197

Fleck S, Van der Zande D, Coppin P (2004) Einsatz eines Laserscanners zur Strukturerfassung und physiologischen Bewertung von Anbausystemen im Obstbau. Erwerbsobstbau 46:97-102

Fleck S, Obertreiber N, Schmidt I, Brauns M, Jungkunst HF, Leuschner C (2007) Terrestrial LiDAR measurements for analysing canopy structure in an old-growth forest. Int Arch Photogramm Remote Sens Spat Inf Sci XXXVI, Part 3/W52, pp $125-129$

Frazer GW, Canham CD, Lertzman KP (1999) Gap light analyzer (GLA), version 2.0: Imaging software to extract canopy structure and gap light transmission indices from true-colour fisheye photographs, users manual and program documentation. Simon Fraser University, Burnaby, British Columbia, and the Institute of Ecosystem Studies, Millbrook, New York

Frazer GW, Fournier RA, Trofymow JA, Hall RJ (2001) A comparison of digital and film fisheye photography for analysis of forest canopy structure and gap light transmission. Agric For Meteorol 109:249-263

Fujimori T (1971) Analysis of forest canopy on the basis of a Tsuga heterophylla stand. Jap J Ecol 59:134-139

Fukushima Y, Hiura T, Tanabe S (1998) Accuracy of the MacArthurHorn method for estimating a foliage profile. Agric For Meteorol 92:203-210

Ganey JL, Block WM (1994) A comparison of two techniques for measuring canopy closure. West J Appl For, Technical Note 9:21-23

Garrison GA (1949) Uses and modifications for the "Moosehorn" crown closure estimator. J Forest 47:733-735

Gong P, Biging GS, Lee SM, Mei X, Sheng Y, Pu R, Xu B, Scharz KP, Mostafa M (1998) Photo ecometrics for forest inventory. In: Hill DA, Leckie DG (eds) Automated interpretation of high spatial resolution digital imagery for forestry, Victoria, British Columbia, Canada. Natural Resources Canada, Canadian Forest Service, Pacific Forestry Centre, Victoria, British Columbia, pp 357-364

Goodall DW (1952) Some considerations in the use of point quadrats for the analysis of vegetation. Aust J Sci Res B 5:1-41

Gower ST, Kucharik CJ, Norman JM (1999) Direct and indirect estimation of leaf area index, fAPAR and net primary production of terrestrial ecosystems. Remote Sens Environ 70:29-51

Groeneveld DP (1997) Vertical point quadrat sampling and an extinction factor to calculate leaf area index. J Arid Environ $36: 475-485$

Guevara-Escobar A, Tellez J, Gonzales-Sosa E (2005) Use of digital photography for analysis of canopy closure. Agroforestr Syst 65:175-185

Haala N, Reulke R, Thies M, Aschoff T (2004) Combination of terrestrial laser scanning with high resolution panoramic images for investigations in forest applications and tree species recognition.
Proceedings of the ISPRS Working Group V/1, Panoramic Photogrammetry Workshop. International Archives of Photogrammetry, Remote Sensing and Spatial Information Sciences Vol XXXIV, Part 5/W16

Hardy JP, Melloh R, Koenig G, Marks D, Winstral A, Pomeroy JW, Link T (2004) Solar radiation transmission through conifer canopies. Agric For Meteorol 126:257-270

Hashimoto R (1990) Analysis of the morphology and structure of crowns in a young sugi Cryptomeria japonica stand. Tree Physiol 6:119-134

Heller H (1971) Estimation of photosynthetically active leaf area in forests. In: Ellenberg $\mathrm{H}$ (ed) Ecological studies 2: integrated experimental ecology-methods and results of ecosystem research in the German solling project. Springer, Berlin, pp 29-31

Henning G, Radtke PJ (2006) Ground-based laser imaging for assessing the three-dimensional forest canopy structure. Photogramm Eng Remote Sens 72:1349-1358

Herbert TJ (1987) Area projections of fisheye photographic lenses. Agric For Meteorol 39:215-223

Hill R (1924) A lens for whole sky photographs. Q J Roy Meteor Soc 50:227-235

Hopkinson C, Chasmer L, Young-Pow C, Treitz P (2004) Assessing forest metrics with a ground-based scanning LIDAR. Can J For Res 34:573-583

Hosoi F, Omasa K (2007) Factors contributing to accuracy in the estimation of the woody canopy leaf area density profile using 3D portable LIDAR imaging. J Exp Bot 58:3463-3473

Hyyppä J, Hyyppä H, Leckie D, Gougeon F, Yu X, Maltamo M (2008) Review of methods of smallfootprint airborne laser scanning for extracting forest inventory data in boreal forests. Int J Remote Sens 29:1339-1366

Jarvis PG, Leverenz JW (1983) Productivity of temperate, deciduous and evergreen forests. In: Lange OL, Nobel PS, Osmond CB, Ziegler H (eds) Encyclopedia of plant physiology, new series, physiological plant ecology, vol. 12D, IV. Springer, Berlin, pp 233-280

Jennings SB, Brown ND, Sheil D (1999) Assessing forest canopies and understorey illumination: canopy closure, canopy cover and other measures. Forestry 72:59-73

Johansson T (1985) Estimating canopy density by the vertical tube method. For Ecol Manag 11:139-144

Jonckheere I, Fleck S, Nackaerts K, Muys B, Coppin P, Weiss M, Baret F (2004) Review of methods for in situ leaf area index determination: part I. Theories, sensors and hemispherical photography. Agric For Meteorol 121:19-35

Keane RE, Reinhardt ED, Gray K, Reardon J (2005) Estimating forest canopy bulk density using six indirect methods. Can J For Res 35:724-739

Kira T, Shinozaki K, Hozumi K (1969) Structure of forest canopies as related to primary productivity. Plant Cell Physiol 10:129-142

Knight DH (1973) Leaf area dynamics of a shortgrass prairie in Colorado. Ecol 54:891-896

Knowles RL, Horvath GC, Carter MA, Hawke MF (1999) Developing a canopy closure model to predict overstorey/understorey relationships in Pinus radiata silvopastoral systems. Agroforest Syst 43:109-119

Kobayashi H, Iwabuchi H (2008) A coupled 1-D atmosphere and 3-D canopy radiative transfer model for canopy reflectance, light environment, and photosynthesis simulation in a heterogeneous landscape. Remote Sens Environ 112:173-185

Koike F (1985) Reconstruction of two-dimensional tree and forest canopy profiles using photographs. J Appl Ecol 22:921-929

Koike F (1989) Foliage-crown development and interaction in Quercus gilva and Q. acuta. J Ecol 77:92-111

Koike F, Tabata H, Malla SB (1990) Canopy structures and its effect on shoot growth and flowering in subalpine forests. Vegetatio $86: 101-113$ 
Korhonen L, Korhonen KT, Rautiainen M, Stenberg P (2006) Estimation of forest canopy cover: a comparison of field measurement techniques. Silva Fenn 40:577-588

Kucharik CJ, Norman JM, Gower ST (1998) Measurements of branch area and adjusting leaf area index indirect measurements. Agric For Meteorol 91:69-88

Kucharik CJ, Norman JM, Gower ST (1999) Characterization of radiation regimes in nonrandom forest canopies: theory, measurements, and a simplified modeling approach. Tree Physiol 19:695706

Kurachi N, Hagigara A, Hozumi K (1986) Distribution of leaf- and branch-biomass density within a crown of Japanese larch and its relationship to primary production: analysis by Sainome-cutting. In: Fujimori T, Whitehead D (eds) Crown and canopy structure in relation to productivity. Forestry and Forest Products Research, Ibaraki, pp 308-322

Lang ARG (1990) An instrument for measuring canopy structure. In: Goel NS, Norman JM (eds) Instrumentation for studying vegetation canopies for remote sensing in optical and thermal infrared regions. Harwood Academic, UK, pp 66-71

Lang ARG, Yueyuin X (1986) Estimation of leaf area index from transmission of direct sunlight in discontinuous canopies. Agric For Meteorol 7:229-243

Lang ARG, Yueqin X, Norman JM (1985) Crop structure and the penetration of direct sunlight of direct sunlight. Agric For Meteorol 35:83-101

Larcher W (2003) Physiological plant ecology-ecophysiology and stress physiology of functional groups, 4th edn. Springer, Berlin

Law BE, Cescatti A, Baldocchi DD (2001) Leaf area distribution and radiative transfer in open-canopy forests: implications for mass and energy exchange. Tree Physiol 21:777-787

Leblanc SG, Chen JM, Kwong M (2002) Tracing radiation and architecture of canopies. TRAC manual version 2.1.3. Natural Resources Canada

Leblanc SG, Chen JM, Fernandes R, Deering DW, Conley A (2005) Methodology comparison for canopy structure parameters extraction from digital hemispherical photography in boreal forests. Agric For Meteorol 129:187-207

Lefsky MA, Harding D, Cohen WB, Parker G, Shugart HH (1999) Surface LIDAR remote sensing of basal area and biomass in deciduous forests of eastern Maryland, USA. Remote Sens Environ 67:83-98

Lemmon PE (1956) A spherical densiometer for estimating forest overstory density. For Sci 2:314-320

Lemmon PE (1957) A new instrument for measuring forest overstory density. J For 55:667-668

Lendzion J, Leuschner C (2008) Growth of European beech (Fagus sylvatica L.) saplings is limited by elevated atmospheric vapour pressure deficits. For Ecol Manag 256:648-655

Levy EB, Madden EA (1933) The point method of pasture analysis. NZ J Agric 46:267-279

Li-Cor D (1992) Plant canopy analyser operating manual. Li-Cor Inc., Lincoln, NE, USA

Loudermilk EL, Singhania A, Fernandez JC, Hiers JK, O’Brien JJ, Cropper WP Jr., Slatton KC, Mitchell RJ (1997) Application of ground-based LIDAR for fine-scale forest fuel modeling. In: Butler BW, Cook W (eds) The fire environment-innovations, management, and policy. Conference proceedings 2007. Destin, FL. Proceedings. U.S. Department of Agriculture, Forest Service, Rocky Mountain Research Station, Fort Collins, 26-30 March 2007, p 662

Lovell JL, Jupp DLB, Culvenor DS, Coops NC (2003) Using airborne and ground-based ranging LIDAR to measure canopy structure in Australian forests. Can J Remote Sens 29:607-622

Lowman MD (1988) Litterfall and leaf decay in three Australian rainforest formations. J Ecol 76:451-465
Luizao FJ (1989) Litter production and mineral element input to the forest floor in a central Amazonian forest. GeoJournal 19:407417

MacArthur RH, Horn HS (1969) Foliage profile by vertical measurements. Ecology 50:802-804

Macfarlane C, Coote M, White DA, Adams DA (2000) Photographic exposure affects indirect estimation of leaf area in plantations of Eucalyptus globulus Labill. Agric For Meteorol 100:155-168

Machado JL, Reich PB (1999) Evaluation of several measures of canopy openness as predictors of photosynthetic photon flux density in deeply shaded conifer-dominated forest understory. Can J For Res 29:1438-1444

Madgwick HAI, Brumfield GL (1969) The use of hemispherical photographs to assess light climate in the forest. J Ecol 57:537542

Marshall JK (1968) Methods of leaf area measurement of large and small leaf samples. Photosynthetica 2:41-47

Marshall JD, Waring RH (1986) Comparison of methods of estimating leaf-area index in old-growth Douglas-fir. Ecology 67:975-979

Martens SN, Ustin SL, Rousseau RA (1993) Estimation of tree canopy leaf area index by gap fraction analysis. For Ecol Manag 61:91108

McIntyre BM, Scholl MA, John T (1990) A quantitative description of a deciduous forest canopy using a photographic technique. For Sci 36:381-393

Means JE, Hansen HA, Koerper GJ, Alaback PB, Klopsch MW (1994) Software for computing plant biomass-BIOPAK users guide. Gen. Tech. Rep. PNW-GTR-340. US Department of Agriculture, Forest Service, Pacific Northwest Research Station, Portland, p 180

Monsi M, Saeki T (1953) Über den Lichtfaktor in den Pflanzengesellschaften und seine Bedeutung für die Stoffproduktion. Jap J Bot 14:22-52

Morsdorf F, Kötz B, Meier E, Itten KI, Allgöwer B (2006) Estimation of LAI and fractional cover from small footprint airborne laser scanning data based on gap fraction. Remote Sens Environ 104:50-61

Mussche S, Smason R, Nachtergale L, Schrijver AD, Lemeur R, Lust $\mathrm{N}$ (2001) A comparison of optical and direct methods for monitoring the seasonal dynamics of leaf area index in deciduous forests. Silva Fenn 35:373-384

Nackaerts K, Wagendorp T, Coppin P, Muys B, Gombeer R (1999) A correction of indirect LAI measurements for a non-random distribution of needles on shoots. Proceedings of ISSSR 1999, Systems and Sensors for the New Millennium, Las Vegas, NV, 31 October-4 November

Næsset E, Gobakken T, Holmgren J, Hyyppä H, Hyyppä J, Maltamo M, Nilsson M, Olsson H, Persson Å, Söderman U (2004) Laser scanning of forest resources: the Nordic experience. Scand J For Res 19:482-499

Niklas KJ (1994) Plant allometry. The scaling of form and process. University of Chicago Press, Chicago

Nilson T (1971) A theoretical analysis of the frequency of gaps in plant stands. Agric Meteorol 8:25-38

Nilson T, Ross V (1979) Characterization of the transparency of a forest canopy by fisheye photographs. Spruce forest ecosystem structure and ecology. Estonian Contributions to the International Biological Programme. In: Frey T (ed) Progress Report No. 12, Tartu, 1979, pp 117-130

Norman JM, Campbell GS (1989) Canopy structure. In: Pearcy RW, Ehleringer J, Mooney HA, Rundel PW (eds) Plant physiological ecology: field methods and instrumentation. Chapman and Hall, New York, pp 301-325

Olsthoorn AFM, Bartelink HH, Gardiner JJ, Pretzsch H, Hekhuis HJ, Franc A (1999) Management of mixed-species forest: silviculture and economics. IBN Sci Contrib 15:1-389 
Ondok JP (1984) Simulation of stand geometry in photosynthetic models based on hemispherical photographs. Photosynthetica 18:231-239

Ovington JD (1963) Flower and seed production. A source of error in estimating woodland production, energy flow and mineral cycling. Oikos 14:148-153

Parker GG, Harding DJ, Berger ML (2004) A portable LIDAR system for rapid determination of forest canopy structure. Proceedings of 20th ISPRS Congress 114-119

Pfeifer N, Gorte B, Winterhalder D (2004) Automatic reconstruction of single trees from terrestrial laser scanner data. Proceedings of 20th ISPRS Congress 114-119

Pope DJ, Lloyd PS (1975) Hemispherical photography, topography, and plant distribution. In: Evans GC, Bainbridge R, Rackham O (eds) Light as an ecological factor II. Blackwell, Oxford, pp 385408

Porté A, Trichet P, Bert D, Loustau D (2002) Allometric relationships for branch tree woody biomass of maritime pine (Pinus pinaster Ait.). For Ecol Manag 158:71-83

Pretzsch H (2006) Species-specific allometric scaling under selfthinning: evidence from long-term plots in forest stands. Oecologia 146:572-583

Pretzsch H, Schütze G (2005) Crown allometry and growing space efficiency of Norway spruce Picea abies L. Karst. and European beech Fagus sylvatica L. in pure and mixed stands. Plant Biol 7:628-639

Radtke PJ, Bolstad PV (2001) Laser point-quadrat sampling for estimating foliage-height profiles in broad-leaved forests. Can J For Res 31:410-418

Rhoads AG, Hamburg SP, Fahey TJ, Siccama TG, Kobe R (2004) Comparing direct and indirect methods of assessing canopy structure in a northern hardwood forest. Can J For Res 34:584-591

Rich PM (1990) Characterizing plant canopies with hemispherical photographs. Remote Sens Rev 5:13-29

Robinson MW (1947) An instrument to measure forest crown cover. For Chron 23:222-225

Running W, Peterson DL, Spanner MA, Teuber KB (1986) Remote sensing of coniferous forest leaf area. Ecology 67:273-276

Sampson DA, Allen HL (1995) Direct and indirect estimates of leaf area index (LAI) for lodgepole and loblolly pine stands. Trees 9:119-122

Schleppi P, Conedera M, Sedivy I, Thimonier A (2007) Correcting non-linearity and slope effects in the estimation of the leaf area index of forest from hemispherical photographs. Agric For Meteorol 144:236-242

Schraml U, Volz K-R (2004) Conversion of coniferous forests-social and political perspectives. Findings from selected countries with special focus on Germany. In: Spiecker H, Hansen J, Klimo E, Skovsgaard JP, Sterba H, von Teuffel K (eds) Norway spruce conversion - options and consequences. Brill, Leiden, pp 97-119

Schwalbe E (2005) Geometric modelling and calibration of fisheye lens camera systems. Proceedings of ISPRS, 2005

Smith ML, Anderson J, Fleadeland M (2008) Forest canopy structural properties. In: Hoover CM (ed) Field measurements for forest carbon monitoring: a landscape scale approach. Springer Science+ Business Media B.V., New York, pp 197-206

Spiecker H (2003) Silvicultural management in maintaining biodiversity and resistance of forests in Europe-temperate zone. J Environ Manag 67:55-65

Staelens J, Nachtergale L, Luyssaert S, Lust N (2003) A model of wind-influenced leaf litterfall in a mixed hardwood forest. Can J For Res 33:201-209

Stenberg P, Linder S, Smolander H, Flower-Ellis J (1994) Performance of the LAI-2000 plant canopy analyzer in estimating leaf area index of some Scots pine stands. Tree Physiol 14:981-995
Strickler GS (1959) Use of the densiometer to estimate density of forest canopy on permanent sample plots. U.S. Department of Agriculture, Pacific Northwest Forest and Range Experiment Station-Forest Service, Portland Oregon, Research Note 180, p 5

Stumpf KA (1993) The estimation of forest vegetation cover descriptions using a vertical densitometer. Presented at the Joint Inventory and Biometrics Working Groups session at the SAF National Convention, Indianapolis, IN, November 8-10, 1993

Sumida A (1995) Three dimensional structure of a mixed broadleaved forest in Japan. Vegetatio 119:67-80

Takeda T, Oguma H (2005) Simulation of light environment in Forest. CGER's Supercomputer Activity Report Vol. 12, 2003 CGER1061-2005, CGER/NIES

Takeda T, Oguma H, Tomohito S, Yone Y, Fujinuma Y (2008) Estimating the plant area density of a Japanese larch Larix kaempferi Sarg. plantation using a ground-based laser scanner. Agric For Meteorol 48:428-438

Tanner EVJ (1980) Litterfall in montane rain forests of Jamaica and its relation to climate. J Ecol 68:833-848

Thies M, Spiecker H (2004) Evaluation and future prospects of terrestrial laser scanning for standardized forest inventories. In: Thies M, Koch B, Spiecker H, Weinacker H (eds) Laserscanners for forest and landscape assessment. ISPRSInternational Archives of Photogrammetry, Remote Sensing and Spatial Information Sciences XXXVI, Part 8/W2, pp 192197

Thies M, Pfeifer N, Winterhalder D, Gorte BGH (2004) Threedimensional reconstruction of stems for assessment of taper, sweep and lean based on laser scanning of standing trees. Scand J For Res 19:571-581

Thimonier A, Sedivy I, Schleppi P (2010) Estimating leaf area index in different types of mature forest stands in Switzerland: a comparison of methods. Eur J For Res 129:543-562

Tickle PK, Lee A, Lucas RM, Austin J, Witte C (2006) Quantifying Australian forest floristics and structure using small footprint LiDAR and large scale aerial photography. For Ecol Manag 223:379-394

Vales DJ, Bunnell FL (1988) Comparison of methods for estimating forest overstory cover. I. Observer effects. Can J For Res 18:606-609

Van der Zande D, Hoet W, Jonckheere I, van Aardt J, Coppin P (2006) Influence of measurement set-up of ground-based LiDAR for derivation of tree structure. Agric For Meteorol 141:147-160

Van Hees WWS, Mead BR (2000) Ocular estimates of understory vegetation structure in a closed Picea glauca/Betula papyrifera forest. J Veg Sci 11:195-200

Vanderbilt VC, Bauer ME, Siva LF (1979) Prediction of solar irradiance distribution in a wheat canopy using a laser technique. Agric For Meteorol 20:147-160

von Lüpke B, Ammer C, Bruciamacchie M, Brunner A, Ceitel J, Collet C, Deuleuze C, Di Placido J, Huss J, Jankovic J, Kantor P, Larsen JB, Lexer M, Löf M, Longauer R, Madsen P, Modrzynski J, Mosandl R, Pampe A, Pommerening A, Stefancik J, Tesar V, Thompson R, Zientarski J (2004) Silvicultural strategies for conversion. In: Spiecker H, Hansen J, Klimo E, Skovsgaard JP, Sterba H, von Teuffel K (eds) Norway spruce conversionoptions and consequences. Brill, Leiden, pp 121-164

Walcroft AS, Brown KJ, Schuster WSF, Tissue DT, Turnbull MH, Griffin KL, Whitehead D (2005) Radiative transfer and carbon assimilation in relation to canopy architecture, foliage area distribution and clumping in a mature temperate rainforest canopy in New Zealand. Agric For Meteorol 135:326339

Walklate PJ (1989) A laser scanning instrument for measuring crop geometry. Agric For Meteorol 46:275-284 
Walters J, Soos J (1962) The gimbal sight for the projection of crown radius. University of British Columbia, Faculty of Forestry, Research Note No. 39

Wang YS, Miller DR, Welles JM, Heisler GM (1992) Spatial variability of canopy foliage in an oak forest estimated with fisheye sensors. For Sci 38:854-865

Waring RH, Schroeder PE, Oren R (1982) Application of the pipe model theory to predict canopy leaf area. Can J For Res 12:556-560

Watt PJ, Donoghue DNM (2005) Measuring forest structure with terrestrial laser scanning. Int J Remote Sens 26:1437-1446

Watt PJ, Donoghue DNM, Dunford RW (2003) Forest parameter extraction using terrestrial laser scanning. Workshop on Airborne Laser Scanning of Forests, September 2003

Weiss M, Baret F, Smith GJ, Jonckheere I, Coppin P (2004) Review of methods for in situ leaf area index LAI determination, part II. Estimation of LAI, errors and sampling. Agric For Meteorol 121:37-53

Welles JM (1990) Some indirect methods of estimation canopy stucture. In: Goel NS, Norman JM (eds) Instrumentation for studying vegetation canopies for remote sensing in optical and thermal infrared regions. Hardwood Academic, UK, pp 31-43
Welles JM, Cohen SC (1996) Canopy structure measurement by gap fraction analysis using commercial instrumentation. J Exp Bot 47:1335-1342

Welles JM, Norman JM (1991) Instrument for indirect measurement of canopy architecture. Agron J 83:818-825

Whitehead D, Grace JC, Godfrey MS (1990) Architectural distribution of foliage in individual Pinus radiata D. Don crowns and the effects of clumping on radiation interception. Tree Physiol 7:135-155

Whittaker RH, Woodwell GM (1968) Dimension and production relations of trees and shrubs in the Brookhaven Forest, New York. Ecology 56:1-25

Wilson JW (1959) Analysis of the spatial distribution of foliage by two-dimensional point quadrats. New Phytol 58:92-99

Wilson JW (1960) Inclined point quadrats. New Phytol 59:1-8

Wilson JW (1963) Estimation of foliage denseness and foliage angle by inclined point quadrats. Aust J Bot 11:95-105

Wilson JW (1965) Stand structure and light penetration. I. Analysis by point quadrats. J Appl Ecol 2:383-390

Zhang Y, Chen JM, Miller JR (2005) Determining digital hemispherical photograph exposure for leaf area index estimation. Agric For Meteorol 133:166-181 